\title{
MATHEMATICAL ANALYSIS OF NON-NEWTONIAN NANOFLUID TRANSPORT PHENOMENA PAST A TRUNCATED CONE WITH NEWTONIAN HEATING
}

\author{
N. Nagendra ${ }^{*}$, C. H. Amanulla ${ }^{2}$ and M. Suryanarayana Reddy ${ }^{3}$ \\ ${ }^{1}$ Department of Mathematics, Madanapalle Institute of Technology and Science, Madanapalle-517325, India. \\ *Email: nagsvu76@gmail.com \\ ${ }^{2}$ Department of Mathematics, Jawaharlal Nehru Technological University, Anantapur, Anantapuramu-515002, India. \\ Email: amanullamsc@gmail.com \\ ${ }^{3}$ Department of Mathematics, JNTUA College of Engineering, Pulivendula-516390, India. \\ Email: machireddysnr.maths@jntua.ac.in
}

\begin{abstract}
:
In the present study, we analyze the heat, momentum and mass (species) transfer in external boundary layer flow of Casson nanofluid past a truncated cone surface with Biot Number effect is studied theoretically. The effects of Brownian motion and thermophoresis are incorporated in the model in the presence of both heat and nanoparticle mass transfer Biot Number effect. The governing partial differential equations (PDEs) are transformed into highly nonlinear, coupled, multi-degree non-similar partial differential equations consisting of the momentum, energy and concentration equations via appropriate non-similarity transformations. These transformed conservation equations are solved subject to appropriate boundary conditions with a second order accurate finite difference method of the implicit type. The influences of the emerging parameters i.e. Casson fluid parameter $(\beta)(\geq 1)$, Brownian motion parameter $(N b)$ thermophoresis parameter $(N t)$, Lewis number $($ Le $)(\geq 5)$, Buoyancy ratio parameter $(N)(\geq 0)$ Prandtl number $(\operatorname{Pr})(7 \leq \operatorname{Pr} \leq 100)$ and Biot number (Bi) $(0.25 \leq B i \leq 1)$ on velocity, temperature and nano-particle concentration distributions is illustrated graphically and interpreted at length. Validation of solutions with a Nakamura tri-diagonal method has been included. The study is relevant to enrobing processes for electric-conductive nano-materials of potential use in aerospace and other industries.
\end{abstract}

Keywords: Nanoparticles; species diffusion; steady flow; Casson viscoplastic model.

\section{NOMENCLATURE}

$\mathrm{Bi}$

C dimensional concentration

$\mathrm{C}_{\mathrm{f}} \quad$ skin friction coefficient

$c_{p} \quad$ specific heat at constant pressure

$D_{B} \quad$ Brownian diffusion coefficient

$\mathrm{D}_{\mathrm{T}} \quad$ thermophoretic diffusion coefficient

f non-dimensional stream function

g acceleration due to gravity

$\mathrm{r} \quad$ cone radius

T Temperature

$\mathrm{u}, \mathrm{v}$ non-dimensional velocity components

$\mathrm{x} \quad$ stream wise coordinate

y transverse coordinate

\section{Greek symbols}

$\beta$

$\alpha$

$\eta$

v

$\gamma$

$\theta$

$\rho$

$\sigma$

$\xi$

$\psi$

Subscripts

W

$\infty$
non-Newtonian Casson parameter thermal diffusivity dimensionless transverse coordinate kinematic viscosity half angle of the truncated cone non-dimensional temperature density of nanofluid electrical conductivity of nanofluid dimensionless steam wise coordinate dimensionless stream function

conditions on the wall free stream conditions 


\section{Introduction}

Nanofluids have evolved into a very exciting and rich frontier in modern nanotechnology. The excitement can be attributed to the robustness of the concept of Nanofluids and the plethora of different applications of this technology (Kuznetsov and Nield, 2010). The properties of Nanofluids need a lot of fine tuning, many seemingly contradicting studies need clarity and validation. Nanofluids have potential applications in microelectronics, fuel cells, rocket propulsion, environmental detoxification, spray coating of aircraft wings, pharmaceutical suspensions, medical sprays etc. These applications of Nanofluids are largely attributable to the enhanced thermal conductivity and Brownian motion dynamics which can be exploited to immense benefit. Nanomaterials work efficiently as new energy materials since they incorporate suspended particles with size as the same as or smaller than the size of de Broglie wave. The use of nanoparticles is now a subject of abundant studies, and aspects of particular interest are Brownian motion and thermophoretic transport. Nanofluids constitute a new class of heat transfer fluids comprising a conventional base fluid and Nano-particles. The nanoparticles are utilized to enhance the heat transfer performance of the base fluids (Choi, 1995). The cooling rate requirements cannot be obtained by the ordinary heat transfer fluids because their thermal conductivity is not adequate. Brownian motion of the nanoparticles enhances the thermal conductivity of base fluids, although there may be many more mechanisms at work which exert a contribution. The concept of Nanofluids was introduced by Choi (1995) wherein he proposed the suspension of nanoparticles in a base fluid such as water, oil, and ethylene glycol. Buongiorno (2006) attempted to explain the increase in the thermal conductivity of such fluids and developed a model that emphasized the key mechanisms in laminar flow as being particle Brownian motion and thermophoresis.

In recent years with the development of hydrophobic surfaces, slip flows have garnered some attention in nanofluid dynamics. Furthermore, the non-Newtonian properties of different nanofluid suspensions have also attracted interest in simulating rheological behavior with different models. Mahatha et al. (2016) investigated dissipative effects in Hydromagnetic boundary layer nanofluid flow past a stretching sheet with Newtonian heating. They found that an increase in the Biot number brings an increase in the nanofluids temperature and nanoparticle volume fraction. Due to convective heat transfer from the hot fluid to the surface of the sheet, the sheet gets heated which in turn increases the heat transfer rate from the sheet to the fluid. Kolsi et al. (2014) explained three-dimensional unsteady natural convection and entropy generation in a cubical enclosure filled with water-A12O3 nanofluid, they analyzed numerical computations of Rayleigh numbers from, solid volume fraction, while the Prandtl number of water is considered constant, Streamlines, is othermal lines, counters of local and total entropy generation and the variation of Bejan number, local and average Nusselt numbers are presented and discussed in detail. Amanulla et al. $(2018,2017)$ investigated velocity and thermal jump conditions on non-Newtonian nanofluid flow from a convective vertical surface. They analyzed the behavior of nano particles on temperature and concentration distributions in detail. Uddin et al. (2016) analyzed anisotropic slip effects on nanofluid bioconvection boundary layers from a translating sheet using MAPLE symbolic quadrature and Lie group methods. Hussein et al. (2014) explained Boltzmann simulation of natural convection heat transfer in an open enclosure filled with $\mathrm{Cu}$-water nanofluid in a presence of magnetic field, they examined the influence of pertinent parameters such as Hartmann number, nanoparticle volume fraction, Rayleigh number and the inclination of magnetic field on the flow and heat transfer characteristics. Rana et al. (2016) used a high-penalty finite element method to simulate two-dimensional flow dissipative viscoelastic nanofluid polymeric boundary layer stretching sheet flow, employing the Reiner-Rivlin second grade non-Newtonian model. They showed that greater polymer fluid viscoelasticity accelerates the flow and increasing Brownian motion and thermophoresis enhances temperatures and reduces heat transfer rates (local Nusselt numbers. Ahmed et al. (2014) investigated boundary layer flow and heat transfer due to permeable stretching tube in the presence of heat source/sink utilizing Nanofluids. Amanulla et al. (2017) discussed Numerical Study of Thermal and Momentum Slip Effects on MHD Williamson Nanofluid from an Isothermal Sphere. Malik et al. (2014) used the Runge-Kutta Fehlberg method to obtain numerical solutions for steady thermal boundary layer flow of a Casson nanofluid flowing over a vertical radially exponentially-stretching cylinder. Many such studies have been communicated and have usually adopted the so-called "active control" boundary condition, based on the Kuznetsov-Nield formulation (2010) for natural convective boundary layer flow of a nanofluid over a vertical surface featuring Brownian motion and thermophoresis. However Kuznetsov and Nield (2014) re-visited their original model, refining this formulation with passive control of nanofluid particle fraction at the boundary rather than active control to be more physically realistic. This recent boundary condition provides one of the motivations for the present research. Chand et al. (2015) explained effect of suspended particles on the onset of thermal convection in a nanofluid layer for more realistic boundary conditions. 
The above studies were generally confined to internal transport. However external boundary layer convection flows also find applications in many technological systems including enrobing polymer coating processes, heat exchanger design, solar collector architecture etc. Prasad et al. (2015) studied two-dimensional nanofluid boundary layer flow from a spherical geometry embedded in porous media with a finite difference scheme. It is found that the reduced Nusselt number is a decreasing function of each dimensionless number, while the reduced Sherwood number is an increasing function of higher Pr and a decreasing function of lower Pr number. Ahmed and Mahdy (2012) investigated magnetic free convection boundary layer nanofluid flow past a truncated cone. In this paper, different models of nanofluid based on diverse formulas for thermal conductivity and dynamic viscosity on the flow and heat transfer characteristics are discussed. Amanulla et al. (2017) considered hydromagnetic convection flow of a Williamson fluid past a vertical truncated cone with thermal and momentum slip effects, the behavior of various parameters like, Williamson viscoelastic fluid parameter, magnetic body force parameter, thermal and velocity (hydrodynamic) slip parameters, stream wise variable and Prandtl number on thermos -fluid characteristics are studied in detail throughout the boundary layer. Amanulla et al. (2017) explained the boundary layer convective flow over a vertical cone with the help of non-similarity transformation solutions. Ram Reddy and Pradeepa (2016) studied viscous dissipation and Soret effects on natural convection flow over a truncated cone in the presence of Biot number. They analyzed different parameters.

The present work, motivated by applications in enrobing dynamics of magnetic nanomaterials (Kleinstreuer and Feng, 2011), examines theoretically and computationally the steady-state transport phenomena in Casson nanofluid flow past a truncated cone with Biot Number effect. Mathematical modelling is developed to derive the equations of continuity, momentum, energy and species conservation based on the Buonjiornio nanofluid model (Buongiorno, 2006). The partial differential boundary layer equations are then transformed into a system of dimensionless non-linear coupled differential boundary layer equations, which is solved with the robust second order accurate Keller box implicit finite difference method. The present work extends significantly earlier simulations of Hussain et al. (2015) (who consider an exponentially stretching surface) to the case of a truncated cone with Biot number effect. An extensive parametric analysis of the influence of a number of parameters (Brownian motion, thermophoresis, Casson non-Newtonian, Biot number, stream wise coordinate) on thermo-diffusive characteristics is conducted. The simulations are also relevant to calendaring in pseudoplastic materials fabrication (Buongiorno, 2006).

\section{Mathematical Model}

We examine steady buoyancy-driven convection heat transfer flow of Casson Nanofluids over a truncated cone. Fig. 1 shows the flow model and associated coordinate system.

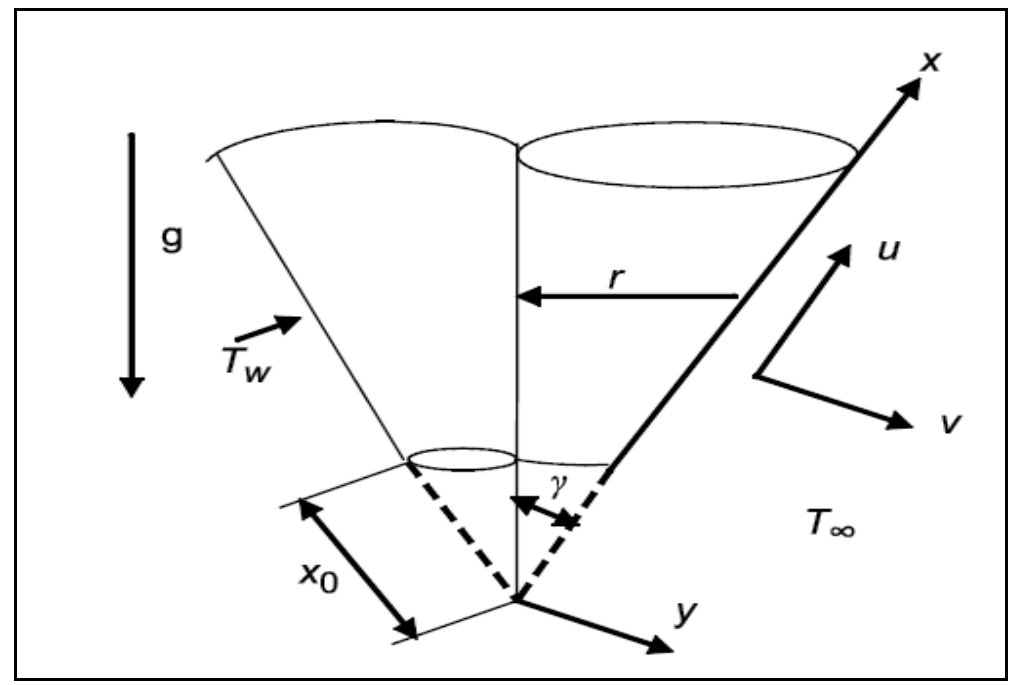

Fig. 1: Physical model and coordinate system 
The nanofluid fluid is taken to be incompressible and a homogenous dilute solution. The $\mathrm{x}$-axis taken along the cone surface measured from the origin and the $\mathrm{y}$-axis is measured normal to the surface, $r=x \sin \gamma$ with ' $\mathrm{r}$ ' denoting the radius of the cone. The gravitational acceleration, $g$ acts downwards. Both the cone and the fluid are maintained initially at the same temperature. Instantaneously they are raised to a temperature $T_{w}>T_{\infty}$ i.e. the ambient temperature of the fluid which remains unchanged.

The appropriate constitutive equations for the Casson non-Newtonian model are:

$\tau_{i j}=\left\{\begin{array}{l}2\left(\mu_{B}+\frac{p_{y}}{\sqrt{2 \pi}}\right) e_{i j}, \pi \geq \pi_{c} \\ 2\left(\mu_{B}+\frac{p_{y}}{\sqrt{2 \pi_{c}}}\right) e_{i j}, \pi<\pi_{c}\end{array}\right.$

in which $\pi=e_{i j} e_{i j}$ and $e_{i j}$ is the $(\mathrm{i}, \mathrm{j})^{\text {th }}$ component of deformation rate, $\pi$ denotes the product of the component of deformation rate with itself, $\pi_{\mathrm{c}}$ shows a critical value of this product based on the non-Newtonian model, $\mu_{B}$ the plastic dynamic viscosity of non-Newtonian fluid and $p_{y}$ the yield stress of fluid.

The Casson model, although relatively simple, is a robust viscoplastic model and describes accurately the shear stress-strain behavior of certain industrial polymers in which flow is not possible prior to the attainment of a critical shear stress. Unlike the Bingham viscoplastic model which has a linear shear rate, the Casson model has a non-linear shear rate. Casson fluid theory was originally propounded to simulate shear thinning (viscosity is reduced with greater shear rates) liquids containing rod-like solids and is equally popular in analysing inks, emulsions, food stuffs (chocolate melts), certain gels and paints (Casson, 1959). More recently it has been embraced in advanced polymeric flow processing (Nakamura, 1994). Incorporating the Casson terms and applying the Buonjiorni nanofluid model, the governing conservation equations, in primitive form, for the regime under investigation i.e. mass continuity, momentum, energy and species, can be written as follows:

$$
\begin{aligned}
& \frac{\partial u}{\partial x}+\frac{\partial v}{\partial y}=0 \\
& u \frac{\partial u}{\partial x}+v \frac{\partial u}{\partial y}=v\left(1+\frac{1}{\beta}\right) \frac{\partial^{2} u}{\partial y^{2}}+\left(g \beta_{T}\left(T-T_{\infty}\right)+g \beta_{C}\left(C-C_{\infty}\right)\right) \cos \gamma \\
& u \frac{\partial T}{\partial x}+v \frac{\partial T}{\partial y}=\alpha \frac{\partial^{2} T}{\partial y^{2}}+\tau\left(D_{B} \frac{\partial C}{\partial y} \frac{\partial T}{\partial y}+\frac{D_{T}}{T_{\infty}}\left(\frac{\partial T}{\partial y}\right)^{2}\right) \\
& u \frac{\partial C}{\partial x}+v \frac{\partial C}{\partial y}=D_{B} \frac{\partial^{2} C}{\partial y^{2}}+\frac{D_{T}}{T_{\infty}} \frac{\partial^{2} T}{\partial y^{2}}
\end{aligned}
$$

The boundary conditions imposed at the cylinder surface and in the free stream are:

$$
\begin{aligned}
& \text { At } y=0, \quad u=0, \quad v=0, \quad-k \frac{\partial T}{\partial y}=h_{1}\left(T_{W}-T\right), \quad C=C_{w} \\
& \text { As } y \rightarrow \infty, u \rightarrow 0, v \rightarrow 0, T \rightarrow T_{\infty}, C \rightarrow C_{\infty}
\end{aligned}
$$

Here $u$ and $v$ are the velocity components in the $x$ - and $y$-directions respectively, $v$ - the kinematic viscosity of the electrically-conducting nanofluid, $\beta$ - is the non-Newtonian Casson parameter respectively, $\rho_{f}$ is the density of fluid, $\sigma$ is the electrical conductivity of the nanofluid, $\alpha$ - the thermal diffusivity of the nanofluid, $T$ - the temperature, respectively. Furthermore $\tau=(\rho c)_{p} /(\rho c)_{f}$ is the ratio of nanoparticle heat capacity 
and the base fluid heat capacity, $C_{p}$ is the specific heat capacity; $D_{B}$ is the Brownian diffusion coefficient; $D_{T}$ is the thermophoretic diffusion coefficient; $k$ is the thermal conductivity of nanofluid; $T_{w}$ and $C_{\infty}$ are the ambient fluid temperature and concentration, respectively.

The stream function $\psi$ is defined by the Cauchy-Riemann equations, $r \boldsymbol{u}=\partial \boldsymbol{\psi} / \partial \boldsymbol{y}$ and $r v=-\partial \psi / \partial x$, and therefore, the continuity equation is automatically satisfied. In order to write the governing equations and the boundary conditions in dimensionless form, the following non-dimensional quantities are introduced.

$$
\begin{aligned}
& \xi=\frac{\bar{x}}{x_{0}}=\frac{x-x_{0}}{x_{0}}, \eta=\frac{y}{x}\left(G r_{x}\right)^{1 / 4}, \psi=r v\left(G r_{x}\right)^{1 / 4} f(\xi, \eta) \\
& \theta(\xi, \eta)=\frac{T-T_{\infty}}{T_{w}-T_{\infty}}, \quad \phi(\xi, \eta)=\frac{C-C_{\infty}}{C_{w}-C_{\infty}}, G r_{x}=\frac{g \beta_{T} \cos \gamma\left(T_{w}-T_{\infty}\right) \bar{x}^{-3}}{v^{2}}
\end{aligned}
$$

The transformed boundary layer equations for momentum, energy and concentration emerge as:

$$
\begin{aligned}
& \left(1+\frac{1}{\beta}\right) f^{\prime \prime \prime}+\left(R+\frac{3}{4}\right) f f^{\prime \prime}-\frac{1}{2} f^{\prime^{2}}+(\theta+N \phi)=\xi\left(f^{\prime} \frac{\partial f^{\prime}}{\partial \xi}-f^{\prime \prime} \frac{\partial f}{\partial \xi}\right) \\
& \frac{\theta^{\prime \prime}}{\operatorname{Pr}}+\left(R+\frac{3}{4}\right) f \theta^{\prime}+N_{b} \phi^{\prime} \theta^{\prime}+N_{t} \theta^{\prime 2}=\xi\left(f^{\prime} \frac{\partial \theta}{\partial \xi}-\theta^{\prime} \frac{\partial f}{\partial \xi}\right) \\
& \frac{\phi^{\prime \prime}}{L e}+\left(R+\frac{3}{4}\right) f \phi^{\prime}+\frac{1}{L e} \frac{N_{b}}{N_{t}} \theta^{\prime \prime}=\xi\left(f^{\prime} \frac{\partial \phi}{\partial \xi}-\phi^{\prime} \frac{\partial f}{\partial \xi}\right)
\end{aligned}
$$

The corresponding transformed dimensionless boundary conditions are:

At $\eta=0, \quad f=0, \quad f^{\prime}=1, \quad \theta^{\prime}=-\xi^{1 / 4} B i(1-\theta(0)), \quad \phi=1$

As $\eta \rightarrow \infty, \quad f^{\prime} \rightarrow 0, \quad \theta \rightarrow 0, \quad \phi \rightarrow 0$

Where $\operatorname{Pr}=\gamma / \alpha$ is Prandtl number; $G c_{x}=g \beta_{C} \cos \gamma\left(T_{w}-T_{\infty}\right) x^{-3} / v^{2}$ is solutal Grashof number; $L e=\gamma / D_{B}$ is the Lewis number; $N t=(\rho c)_{p} D_{T}\left(T_{w}-T_{\infty}\right) /(\rho c)_{f} \gamma T_{\infty}$ is the thermophoresis parameter; $N=G c_{x} / G r_{x}$ is the concentration to thermal buoyancy ratio parameter; $N b=(\rho c)_{p} D_{B}\left(C_{w}-C_{\infty}\right) /(\rho c)_{f} \gamma$ is the Brownian parameter; $B i=h_{1} x_{0} / k G r_{x_{0}}{ }^{1 / 4}$ is the Biot parameter; $R=\xi / 1+\xi$.

All other parameters are defined in the nomenclature. The skin-friction coefficient (cone surface shear stress function), the local Nusselt number (heat transfer rate) and Sherwood number (mass transfer rate) can be defined using the transformations described above with the following expressions:

$$
\begin{aligned}
& \frac{1}{2} G r_{x}^{1 / 4} C_{f}=\left(1+\frac{1}{\beta}\right) f^{\prime \prime}(\xi, 0) \\
& G r_{x}^{-1 / 4} N u=-\theta^{\prime}(\xi, 0) \\
& G r_{x}^{-1 / 4} S h=-\phi^{\prime}(\xi, 0)
\end{aligned}
$$




\section{Numerical Solution with Keller Box Implicit Method}

The strongly coupled, nonlinear conservation equations do not admit analytical (closed-form) solutions. An elegant, implicit difference finite difference numerical method developed by Keller (1970) is therefore adopted to solve the general flow model defined by Equations (8)-(10) with boundary conditions (11). This method is especially appropriate for boundary layer flow equations which are parabolic in nature. It remains one of the most widely applied computational methods in viscous fluid dynamics. Recent problems which have used Keller's method include radiative magnetic forced convection flow (Buongiorno, 2006), stretching sheet Hydromagnetic flow (Bég, 2013), Magnetohydrodynamic Falkner-Skan "wedge" flows (2014), magnetorheological flow from an extending cylinder (2015), Hall magneto-gas dynamic generator slip flows (2016) and radiative-convective Casson slip boundary layer flows $(2015,2016)$ and Jeffrey fluid flows (2015). Keller's method provides unconditional stability and rapid convergence for strongly non-linear flows. It involves four key stages, summarized below.

1) Reduction of the Nth order partial differential equation system to $\mathrm{N}$ first order equations

2) Finite difference discretization of reduced equations

3) Quasilinearization of non-linear Keller algebraic equations

4) Block-tridiagonal elimination of linearized Keller algebraic equations

\subsection{Stage 1: Reduction of the $N^{\text {th }}$ order partial differential equation system to $N$ first order equations}

Equations (8) - (10) and (11) subject to the boundary conditions are first written as a system of first-order equations. For this purpose, we reset Equations (6) - (7) as a set of simultaneous equations by introducing the new variables

$$
\begin{aligned}
& f^{\prime}=u \\
& u^{\prime}=v \\
& \theta=s \\
& s^{\prime}=t \\
& g^{\prime}=p \\
& \left(1+\frac{1}{\beta}\right) v^{\prime}+\left(R+\frac{3}{4}\right) f v-\frac{1}{2} u^{2}+(s+N g)=\xi\left(u \frac{\partial u}{\partial \xi}-v \frac{\partial f}{\partial \xi}\right) \\
& \frac{t^{\prime}}{\operatorname{Pr}}+\left(R+\frac{3}{4}\right) f t+N_{b} \phi^{\prime} t+N_{t} t^{2}=\xi\left(u \frac{\partial s}{\partial \xi}-t \frac{\partial f}{\partial \xi}\right) \\
& \frac{p^{\prime}}{L e}+\left(R+\frac{3}{4}\right) f p+\frac{1}{L e} \frac{N_{b}}{N_{t}} t^{\prime}=\xi\left(u \frac{\partial g}{\partial \xi}-p \frac{\partial f}{\partial \xi}\right)
\end{aligned}
$$

where primes denote differentiation with respect to $\eta$. In terms of the dependent variables, the boundary conditions become:

$$
\begin{aligned}
& \text { At } \eta=0: u=0, f=0, s=1, g=1 \\
& \text { As } \eta \rightarrow \infty: u \rightarrow 0, v \rightarrow 0, s \rightarrow 0, g \rightarrow 0
\end{aligned}
$$




\subsection{Stage 2: Finite difference discretization of reduced boundary layer equations}

A two-dimensional computational grid (mesh) is imposed on the $\xi \eta$ plane as sketched in Fig.2. The stepping process is defined by:

$$
\begin{aligned}
& \eta_{0}=0, \eta_{j}=\eta_{j-1}+h_{j}, j=1,2, \ldots, J, \eta_{J} \equiv \eta_{\infty} \\
& \xi^{0}=0, \xi^{n}=\xi^{n-1}+k_{n}, n=1,2, \ldots, N
\end{aligned}
$$

where $k_{n}$ and $h_{j}$ denote the step distances in the $\xi$ (stream wise) and $\eta$ (span wise) directions respectively.

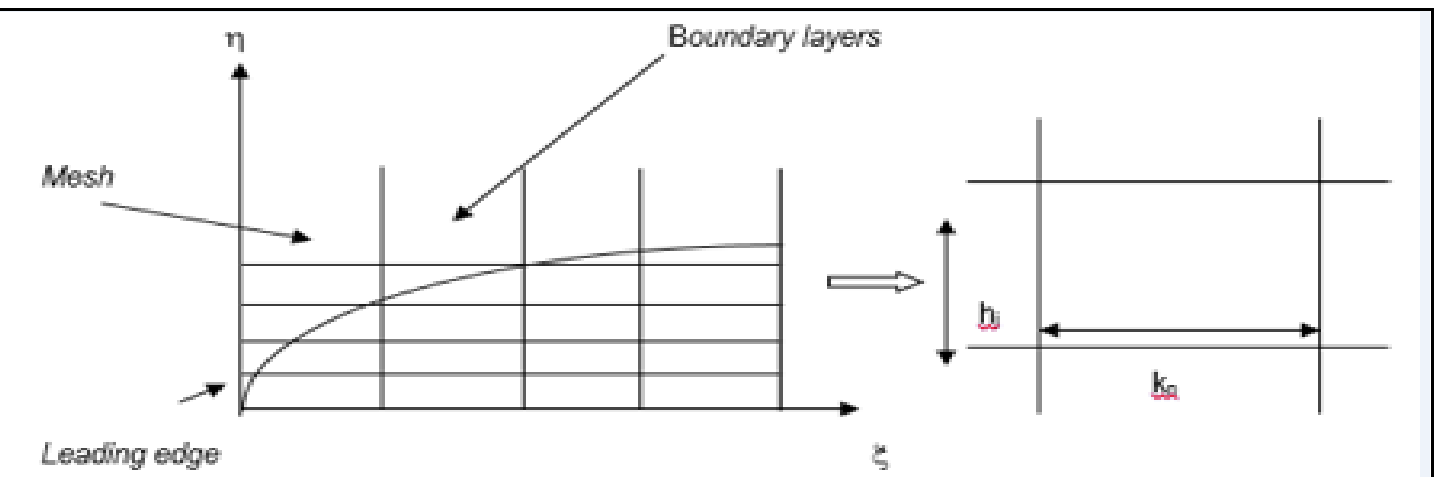

Fig 2: Keller Box element and boundary layer mesh

If $g_{j}^{n}$ denotes the value of any variable at $\left(\eta_{j}, \xi^{n}\right)$, then the variables and derivatives of Eqns. (15) - (22) at $\left(\eta_{j-1 / 2}, \xi^{n-1 / 2}\right)$ are replaced by:

$g_{j-1 / 2}^{n-1 / 2}=\frac{1}{4}\left(g_{j}^{n}+g_{j-1}^{n}+g_{j}^{n-1}+g_{j-1}^{n-1}\right)$

$\left(\frac{\partial g}{\partial \eta}\right)_{j-1 / 2}^{n-1 / 2}=\frac{1}{2 h_{j}}\left(g_{j}^{n}-g_{j-1}^{n}+g_{j}^{n-1}-g_{j-1}^{n-1}\right)$,

$\left(\frac{\partial g}{\partial \xi}\right)_{j-1 / 2}^{n-1 / 2}=\frac{1}{2 k^{n}}\left(g_{j}^{n}-g_{j-1}^{n}+g_{j}^{n-1}-g_{j-1}^{n-1}\right)$

The finite-difference approximation of equations (15) - (22) for the mid-point $\left(\eta_{j-1 / 2}, \xi^{n}\right)$, below:

$h_{j}^{-1}\left(f_{j}^{n}-f_{j-1}^{n}\right)=u_{j-1 / 2}^{n}$,

$h_{j}^{-1}\left(u_{j}^{n}-u_{j-1}^{n}\right)=v_{j-1 / 2}^{n}$,

$h_{j}^{-1}\left(g_{j}^{n}-g_{j-1}^{n}\right)=p_{j-1 / 2}^{n}$,

$h_{j}^{-1}\left(\theta_{j}^{n}-\theta_{j-1}^{n}\right)=t_{j-1 / 2}^{n}$, 


$$
\begin{aligned}
& \left(1+\frac{1}{\beta}\right)\left(v_{j}-v_{j-1}\right)+\left(R+\frac{3}{4}+\alpha\right) \frac{h_{j}}{4}\left[\left(f_{j}+f_{j-1}\right)\left(v_{j}+v_{j-1}\right)\right]-\left(\frac{1}{2}+\alpha\right) \frac{h_{j}}{4}\left(u_{j}+u_{j-1}\right)^{2} \\
& +\frac{h_{j}}{2}\left(s_{j}+s_{j-1}+N\left(g_{j}+g_{j-1}\right)\right)-\frac{\alpha h_{j}}{2} f_{j-1 / 2}^{n-1}\left(v_{j}+v_{j-1}\right)+\frac{\alpha h_{j}}{2} v_{j-1 / 2}^{n-1}\left(f_{j}+f_{j-1}\right)=\left[R_{1}\right]_{j-1 / 2}^{n-1} \\
& \frac{1}{\operatorname{Pr}}\left(t_{j}-t_{j-1}\right)+\left(R+\frac{3}{4}+\alpha\right) \frac{h_{j}}{4}\left[\left(f_{j}+f_{j-1}\right)\left(t_{j}+t_{j-1}\right)\right]-\frac{\alpha h_{j}}{4}\left[\left(u_{j}+u_{j-1}\right)\left(s_{j}+s_{j-1}\right)\right] \\
& +N b \frac{h_{j}}{4}\left[\left(t_{j}+t_{j-1}\right)\left(p_{j}+p_{j-1}\right)\right]+N t \frac{h_{j}}{4}\left(t_{j}+t_{j-1}\right)^{2}+\frac{\alpha h_{j}}{2} s_{j-1 / 2}^{n-1}\left(u_{j}+u_{j-1}\right) \\
& -\frac{\alpha h_{j}}{2} u_{j-1 / 2}^{n-1}\left(s_{j}+s_{j-1}\right)-\frac{\alpha h_{j}}{2} f_{j-1 / 2}^{n-1}\left(t_{j}+t_{j-1}\right)+\frac{\alpha h_{j}}{2} t_{j-1 / 2}^{n-1}\left(f_{j}+f_{j-1}\right)=\left[R_{2}\right]_{j-1 / 2}^{n-1} \\
& \frac{1}{L e}\left(p_{j}-p_{j-1}\right)+\left(R+\frac{3}{4}+\alpha\right) \frac{h_{j}}{4}\left[\left(f_{j}+f_{j-1}\right)\left(p_{j}+p_{j-1}\right)\right]+\frac{B}{L e}\left(t_{j}-t_{j-1}\right) \\
& -\frac{\alpha h_{j}}{4}\left[\left(u_{j}+u_{j-1}\right)\left(g_{j}+g_{j-1}\right)\right]+\frac{\alpha h_{j}}{2} s_{j-1 / 2}^{n-1}\left(u_{j}+u_{j-1}\right)-\frac{\alpha h_{j}}{2} u_{j-1 / 2}^{n-1}\left(g_{j}+g_{j-1}\right) \\
& -\frac{\alpha h_{j}}{2} f_{j-1 / 2}^{n-1}\left(p_{j}+p_{j-1}\right)+\frac{\alpha h_{j}}{2} p_{j-1 / 2}^{n-1}\left(f_{j}+f_{j-1}\right)=\left[R_{2}\right]_{j-1 / 2}^{n-1}
\end{aligned}
$$

Where the following notations applies:

$$
\begin{aligned}
& \alpha=\frac{\xi^{n-1 / 2}}{k_{n}}, \quad B=\frac{N t}{N b} \\
& {\left[R_{1}\right]_{j-1 / 2}^{n-1}=-h_{j}\left[\begin{array}{l}
\left(1+\frac{1}{\beta}\right)\left(\frac{v_{j}-v_{j-1}}{h_{j}}\right)+\left(\frac{1}{2}-\alpha\right)\left(u_{j-1 / 2}\right)^{2}+\left(R+\frac{3}{4}-\alpha\right)\left(f_{j-1 / 2} v_{j-1 / 2}\right) \\
+\left(s_{j-1 / 2}+N g_{j-1 / 2}\right)
\end{array}\right]} \\
& {\left[R_{2}\right]_{j-1 / 2}^{n-1}=-h_{j}\left[\frac{1}{\operatorname{Pr}}\left(\frac{t_{j}-t_{j-1}}{h_{j}}\right)+\left(R+\frac{3}{4}-\alpha\right)\left(f_{j-1 / 2} t_{j-1 / 2}\right)+\alpha\left(u_{j-1 / 2} s_{j-1 / 2}\right)-N b\left(p_{j-1 / 2} t_{j-1 / 2}\right)-N t\left(t_{j-1 / 2}\right)^{2}\right]} \\
& {\left[R_{3}\right]_{j-1 / 2}^{n-1}=-h_{j}\left[\frac{1}{L e}\left(\frac{p_{j}-p_{j-1}}{h_{j}}\right)+\left(R+\frac{3}{4}-\alpha\right)\left(f_{j-1 / 2} p_{j-1 / 2}\right)+\frac{B}{L e}\left(\frac{t_{j}-t_{j-1}}{h_{j}}\right)+\alpha\left(u_{j-1 / 2} g_{j-1 / 2}\right)\right]}
\end{aligned}
$$

The boundary conditions are

$$
f_{0}^{n}=u_{0}^{n}=0, \theta_{0}^{n}=1, u_{J}^{n}=0, v_{J}^{n}=0, \theta_{J}^{n}=0, \varphi_{0}^{n}=1, \varphi_{J}^{n}=0
$$




\subsection{Stage 3: Quasilinearization of non-linear Keller algebraic equations}

If we assume $f_{j-1}^{n-1}, u_{j-1}^{n-1}, v_{j-1}^{n-1}, p_{j-1}^{n-1}, g_{j-1}^{n-1}, s_{j-1}^{n-1}, t_{j-1}^{n-1}$, to be known for $\mathrm{O} \leq \boldsymbol{j} \leq \boldsymbol{J}$, Equations (30) - (36) comprise a system of $7 J+7$ equations for the solution of $7 J+7$ unknowns $f_{j}^{n}, u_{j}^{n}, v_{j}^{n}, p_{j}^{n}, g_{j}^{n}, s_{j}^{n}, t_{j}^{n},, j=0,1,2 \ldots$, $J$. This non-linear system of algebraic equations is linearized by means of Newton's method as elaborated by Keller (1970).

\subsection{Stage 4: Block-tridiagonal elimination of linear Keller algebraic equations}

The linearized version of eqns. (30) - (36) can now be solved by the block-elimination method, since they possess a block-tridiagonal structure since it consists of block matrices. The complete linearized system is formulated as a block matrix system, where each element in the coefficient matrix is a matrix itself. Then, this system is solved using the efficient Keller-box method. The numerical results are affected by the number of mesh points in both directions. After some trials in the $\eta$-direction (radial coordinate) a larger number of mesh points are selected whereas in the $\xi$ direction (tangential coordinate) significantly less mesh points are utilized. $\eta_{\max }$ has been set at 16 and this defines an adequately large value at which the prescribed boundary conditions are satisfied. $\xi_{\max }$ is set at 5.0 for this flow domain. Mesh independence testing is also performed to ensure that the converged solutions are correct. The computer program of the algorithm is executed in MATLAB running on a PC.

\section{Validation with Nakamura Difference Scheme}

The present Keller box method (KBM) algorithm has been tested rigorously and benchmarked in numerous studies by the authors. However to further increase confidence in the present solutions, we have validated the general model with an alternative finite difference procedure due to Nakamura (1994). The Nakamura tridiagonal method (NTM) generally achieves fast convergence for nonlinear viscous flows which may be described by either parabolic (boundary layer) or elliptic (Navier-Stokes) equations. The coupled $7^{\text {th }}$ order system of nonlinear, multi-degree, ordinary differential equations defined by (8)-(10) with boundary conditions (11) is solved using the NANONAK code in double precision arithmetic in Fortran 90, as elaborated by Bég (2013). Computations are performed on an SGI Octane Desk workstation with dual processors and take seconds for compilation. As with other difference schemes, a reduction in the higher order differential equations, is also fundamental to Nakamura's method. The method has been employed successfully to simulate many sophisticated nonlinear transport phenomena problems e.g. magnetized bio-polymer enrobing coating flows (Bég et al., 2014)). Intrinsic to this method is the discretization of the flow regime using an equi-spaced finite difference mesh in the transformed coordinate $(\eta)$ and the central difference scheme is applied on the $\eta$ variable. A backward difference scheme is applied on the $\xi$ variable. Two iteration loops are used and once the solution for $\eta$ has converged, the code progresses to the next $\xi$ station. The partial derivatives for $f, \theta, \phi$ with respect to $\eta$ are as explained evaluated by central difference approximations. An iteration loop based on the method of successive substitution is utilized to advance the solution i.e. march along. The finite difference discretized equations are solved in a step-by-step fashion on the $\eta$-domain in the inner loop and thereafter on the $\xi$ domain in the outer loop. For the energy and nano-particle species conservation Eqns. (9)-(10) which are second order multi-degree ordinary differential equations, only a direct substitution is needed. However a reduction is required for the third order momentum (velocity) boundary layer eqn. (8). We apply the following substitutions:

$P=f$

$Q=\theta$

$R=\phi$

The eqns. (8)-(10) then retract to:

Nakamura momentum equation: 


$$
A_{1} P^{\prime \prime}+B_{1} P^{\prime}+C_{1} P=T_{1}
$$

Nakamura energy equation:

$$
A_{2} Q^{\prime \prime}+B_{2} Q^{\prime}+C_{2} Q=T_{2}
$$

Nakamura nano-particle species equation:

$$
A_{3} R^{\prime \prime}+B_{3} R^{\prime}+C_{3} R=T_{3}
$$

Here $\mathrm{Ai}=1,2,3, \mathrm{Bi}=1,2,3, \mathrm{Ci}=1,2,3$, are the Nakamura matrix coefficients, $\mathrm{T} i=1,2,3$, are the Nakamura source terms containing a mixture of variables and derivatives associated with the respective lead variable $(\mathrm{P}, \mathrm{Q}, \mathrm{R})$. The Nakamura Eqns. (27)-(30) are transformed to finite difference equations and these are orchestrated to form a tridiagonal system which due to the high nonlinearity of the numerous coupled, multi-degree terms in the momentum, energy, nano-particle species and motile micro-organism density conservation equations, is solved iteratively. Householder's technique is ideal for this iteration. The boundary conditions (11) are also easily transformed. Further details of the NTM approach are provided in Nakamura (1994). Comparisons are documented in Table 1 for skin friction and very good correlation is attained. Table 1 further indicates that with Biot Number (Bi) the skin friction is enhanced i.e. the boundary layer flow is accelerated. Also an increase in Casson viscoplastic parameter $(\beta)$ induces a strong retardation in the flow i.e. suppresses skin friction magnitudes. In both cases however positive magnitudes indicate flow reversal is not generated. For accuracy, we compared our results with Yih (1999) and Ram Reddy (2016) and we observed that a very good agreement with previous results as shown in Table2.

\section{Keller Box Method (KBM) Numerical Results and Discussion}

Comprehensive solutions have been obtained with KBM and are presented in Figs. 3 to 10. The numerical problem comprises three dependent thermo-fluid dynamic variables $(f, \theta, \phi)$ and seven multi-physical control parameters, $\operatorname{Pr}, L e, \beta, N, N b, N t, B i$. The influence of stream wise space variable $\xi$ is also investigated. In the present computations, the following default parameters are prescribed (unless otherwise stated): $\mathrm{Pr}=7.0$, $L e=5.0, \beta=2.0, N=0.1, N b=0.02=N t, B i=0.2, \xi=1.0$.

Table 1 Numerical values of skin-friction coefficient $(1+1 / \beta) f^{\prime \prime}(0)$ of $\beta$ with

$$
\operatorname{Pr}=7.0, L e=5.0, N b=0.02=N t, N=0.1, \xi=1.0
$$

\begin{tabular}{|l|l|l|l|}
\hline$\beta$ & $B i$ & $\begin{array}{c}(1+1 / \beta) f^{\prime \prime}(0) \\
(\mathrm{KBM})\end{array}$ & $\begin{array}{c}(1+1 / \beta) f^{\prime \prime}(0) \\
(\mathrm{NTM})\end{array}$ \\
\hline 0.7 & 0.5 & 0.8412 & 0.8411 \\
\hline 1.2 & 0.5 & 0.7605 & 0.7607 \\
\hline 1.6 & 0.5 & 0.7277 & 0.7261 \\
\hline 2.0 & 0.5 & 0.7065 & 0.7061 \\
\hline 1.0 & 0.0 & 0.9070 & 0.9073 \\
\hline & 0.1 & 0.8777 & 0.8775 \\
\hline & 0.2 & 0.8277 & 0.8273 \\
\hline & 0.3 & 0.7848 & 0.7844 \\
\hline
\end{tabular}


Table 2: Comparison analysis of $f^{\prime \prime}(\xi, 0)$ and $-\theta^{\prime}(\xi, 0)$, for different values of $\mathrm{Pr}$ when $N b=0=N t, N=0, \xi=0$ and $\beta \rightarrow \infty, B i \rightarrow \infty$

\begin{tabular}{|l|c|l|l|l|l|l|}
\hline \multirow{2}{*}{ Pr } & \multicolumn{3}{|c|}{$f^{\prime \prime}(\xi, 0)$} & \multicolumn{3}{c|}{$-\theta^{\prime}(\xi, 0)$} \\
\cline { 2 - 7 } & $\begin{array}{c}\text { Yih } \\
(1999)\end{array}$ & $\begin{array}{c}\text { Ram Reddy } \\
(2016)\end{array}$ & Present & $\begin{array}{c}\text { Yih } \\
(1999)\end{array}$ & $\begin{array}{c}\text { Ram Reddy } \\
(2016)\end{array}$ & Present \\
\hline 0.01 & 1.3968 & 1.38914 & 1.38901 & 0.057 & 0.05954 & 0.05965 \\
\hline 0.1 & 1.2144 & 1.21502 & 1.21510 & 0.1629 & 0.16273 & 0.16281 \\
\hline 1 & 0.9084 & 0.90819 & 0.90821 & 0.4012 & 0.40103 & 0.40112 \\
\hline 10 & 0.5927 & 0.59283 & 0.59787 & 0.8266 & 0.82684 & 0.82692 \\
\hline 100 & 0.3559 & 0.35594 & 0.35599 & 1.5493 & 1.54953 & 1.54963 \\
\hline
\end{tabular}

Table 3: Effects of $\beta, \mathrm{Nb}$ and $N t$ on $f^{\prime \prime}(\xi, 0),-\theta^{\prime}(\xi, 0)$ and $-\phi^{\prime}(\xi, 0)$ over cone

\begin{tabular}{|c|c|c|c|c|c|}
\hline$\beta$ & $\mathrm{Nb}$ & $N t$ & $f^{\prime \prime}(\xi, 0)$ & $-\theta^{\prime}(\xi, 0)$ & $-\phi^{\prime}(\xi, 0)$ \\
\hline 1.0 & \multirow{4}{*}{0.02} & \multirow{8}{*}{0.02} & 0.4249 & 0.2280 & 0.4229 \\
\hline 2.0 & & & 0.3913 & 0.2430 & 0.4489 \\
\hline 3.0 & & & 0.3781 & 0.2493 & 0.4597 \\
\hline 4.0 & & & 0.3711 & 0.2528 & 0.4656 \\
\hline \multirow{8}{*}{2.0} & 0.2 & & 0.3813 & 0.2409 & 0.5426 \\
\hline & 0.4 & & 0.3854 & 0.2382 & 0.5475 \\
\hline & 0.6 & & 0.3863 & 0.2360 & 0.5492 \\
\hline & 0.8 & & 0.3876 & 0.2352 & 0.5499 \\
\hline & & 0.05 & 0.4022 & 0.2503 & 0.2821 \\
\hline & & 0.08 & 0.4131 & 0.2574 & 0.1040 \\
\hline & & 0.1 & 0.4203 & 0.2622 & -0.0220 \\
\hline & & 0.2 & 0.4559 & 0.2864 & -0.7397 \\
\hline
\end{tabular}

Table 4: Effects of $\xi$,Prand Le on $f^{\prime \prime}(\xi, 0),-\theta^{\prime}(\xi, 0)$ and $-\phi^{\prime}(\xi, 0)$ over cone

\begin{tabular}{|c|c|c|c|c|c|}
\hline$\xi$ & $\mathrm{Pr}$ & Le & $f^{\prime \prime}(\xi, 0)$ & $-\theta^{\prime}(\xi, 0)$ & $-\phi^{\prime}(\xi, 0)$ \\
\hline 1.0 & \multirow{5}{*}{7.0} & \multirow{10}{*}{5.0} & 0.3913 & 0.2430 & 0.4489 \\
\hline 2.0 & & & 0.3786 & 0.2508 & 0.4668 \\
\hline 3.0 & & & 0.3717 & 0.2557 & 0.4759 \\
\hline 4.0 & & & 0.3675 & 0.2596 & 0.4810 \\
\hline 5.0 & & & 0.3647 & 0.2624 & 0.4844 \\
\hline \multirow{10}{*}{1.0} & 10 & & 0.3707 & 0.2730 & 0.4043 \\
\hline & 25 & & 0.3266 & 0.3711 & 0.2730 \\
\hline & 50 & & 0.2953 & 0.4747 & 0.1496 \\
\hline & 75 & & 0.2801 & 0.5548 & 0.0602 \\
\hline & 100 & & 0.2700 & 0.6246 & -0.0154 \\
\hline & & 10 & 0.3769 & 0.2370 & 0.6423 \\
\hline & & 20 & 0.3652 & 0.2325 & 0.8773 \\
\hline & & 30 & 0.3594 & 0.2305 & 1.0380 \\
\hline & & 40 & 0.3557 & 0.2293 & 1.1567 \\
\hline & & 50 & 0.3530 & 0.2285 & 1.2695 \\
\hline
\end{tabular}


Table 5: Effects of $B i$ and $N$ on $f^{\prime \prime}(\xi, 0),-\theta^{\prime}(\xi, 0)$ and $-\phi^{\prime}(\xi, 0)$ over cone

\begin{tabular}{|l|l|l|l|l|}
\hline$B i$ & $N$ & $f^{\prime \prime}(\xi, 0)$ & $-\theta^{\prime}(\xi, 0)$ & $-\phi^{\prime}(\xi, 0)$ \\
\hline 0.2 & \multirow{4}{*}{0.1} & 0.3913 & 0.2430 & 0.4489 \\
\cline { 4 - 5 } & 0.5 & 0.5694 & 0.5094 & 0.3987 \\
\cline { 4 - 5 } & 0.6244 & 0.6065 & 0.3728 \\
\cline { 1 - 3 } 0.6 & & 0.6513 & 0.6563 & 0.3587 \\
\cline { 3 - 5 } 0.8 & 0.6673 & 0.6867 & 0.3497 \\
\hline 1.0 & 0.0 & 0.3162 & 0.2239 & 0.4117 \\
\hline \multirow{4}{*}{0.2} & 0.2 & 0.4617 & 0.2584 & 0.4784 \\
\cline { 3 - 5 } & 0.3 & 0.5288 & 0.2721 & 0.5029 \\
\cline { 3 - 5 } & 0.4 & 0.5930 & 0.2836 & 0.5244 \\
\cline { 3 - 5 } & 0.5 & 0.6551 & 0.2915 & 0.5453 \\
\hline
\end{tabular}

Table 3 presents the influence of increasing non-Newtonian Casson parameter $\beta$, Brownian motion parameter $\mathrm{Nb}$ and thermophoretic parameter $\mathrm{Nt}$ on skin friction, heat transfer rate and mass transfer rate. Where heat transfer rate and mass transfer rate both are accelerate with increasing Casson parameter $\beta$, but skin friction is decreased. With increasing Brownian motion parameter $\mathrm{Nb}$, the skin friction is generally increased, whereas heat transfer rate is decreased. Mass transfer rate is however increased with increasing Brownian motion parameter $\mathrm{Nb}$. With increasing thermophoretic parameter $N t$, the skin friction is slightly increased, whereas heat transfer rate is increased. Mass transfer rate is however decreased with increasing thermophoretic parameter $N t$.

Tables 4 presents the influence of increasing Prandtl number on skin friction, heat transfer rate and mass transfer rate. With increasing Prandtl number, the skin friction is generally decreased, whereas heat transfer rate is enhanced. Mass transfer rate is however decreased with increasing Prandtl number. Whereas increas ing $\xi$, decreases the Skin friction but increases the Nusselt number and Sherwood number. With increasing Lewis number, skin friction and Nusselt number both are reduces, but mass transfer rate is enhanced.

Table 5 presents the influence of the Biot number (Bi) on skin friction, heat transfer rate and Sherwood Number It is observed that the increasing $\mathrm{Bi}$, increases both skin friction and heat transfer rate, but reduced Sherwood Number. And increasing N, increases Skin friction, heat transfer rate and Sherwood Number.

Figs. 3(a) - 3(c) illustrate the effect of the Casson Viscoplastic parameter, $\beta$ on velocity $\left(f^{\prime}\right)$, temperature $(\theta)$ and concentration $(\phi)$ profiles. With increasing, $\beta$ values, initially close to the cylinder surface, fig. 4a shows that the flow is strongly decelerated. However, further from the surface, the converse response is induced in the flow. This may be related to the necessity for a yield stress to be attained prior to viscous flow initiation in Viscoplastic shear-thinning Nanofluids. Within a short distance of the cylinder surface, however a strong acceleration is generated with greater Casson parameter. This serves to decrease momentum boundary layer thickness effectively. A similar observation has been reported by for example, Mustafa and Khan (2015). The Viscoplastic parameter modifies the shear term $f^{\prime \prime \prime}$ in the momentum boundary layer equation (8) with an inverse factor, $1 / \beta$, and effectively assists momentum diffusion for $\beta>1$. This leads to a thinning in the hydrodynamic boundary layer and as sociated deceleration. The case $\beta=0$ which corresponds to a Newtonian fluid is not considered. An increase in Viscoplastic parameter however decreases both temperature and Nanoparticle concentration magnitudes throughout the boundary layer, although the reduction is relatively weak. Thermal and nanoparticle concentration boundary layer thickness are both suppressed with greater viscoplasticity of the nanofluid.

Figs. 4(a)-4(c) depicts the effect of Prandtl number $(P r)$ on the velocity $\left(f^{\prime}\right)$, temperature $(\theta)$ and nanoparticle concentration $(\phi)$ distributions with transverse coordinate $(\eta)$. Fig. 4a shows that with increasing Prandtl number there is a strong deceleration in the flow. The Prandtl number expresses the ratio of momentum diffusion rate to thermal diffusion rate. When $\operatorname{Pr}$ is unity both momentum and heat diffuse at the same rate and the velocity and thermal boundary layer thicknesses are the same. With $\operatorname{Pr}>1$ there is a progressive decrease in thermal diffusivity relative to momentum diffusivity and this serves to retard the boundary layer flow. Momentum boundary layer thickness therefore grows with Prandtl number on the surface of the cone. It is also noteworthy that the peak velocity which is achieved close to the cylinder surface is systematically displaced 
closer to the surface with greater Prandtl number. The asymptotically smooth profiles of velocity which decays to zero in the free stream, also confirm the imposition of an adequately large infinity boundary condition. Fig. $4 \mathrm{~b}$ indicates that increasing Prandtl number also suppresses temperatures in the boundary layer and therefore reduces thermal boundary layer thickness. Prandtl number is inversely proportional to thermal conductivity of the viscoplastic nanofluid. Higher thermal conductivity implies lower Prandtl number and vice versa. With greater Prandtl number, thermal conductivity is reduces and this inhibits thermal conduction heat transfer which cools the boundary layer.

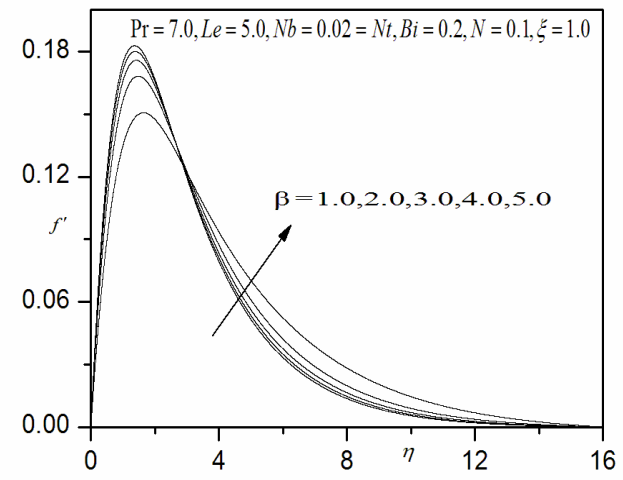

Fig 3(a): Effect of $\beta$ on velocity profiles

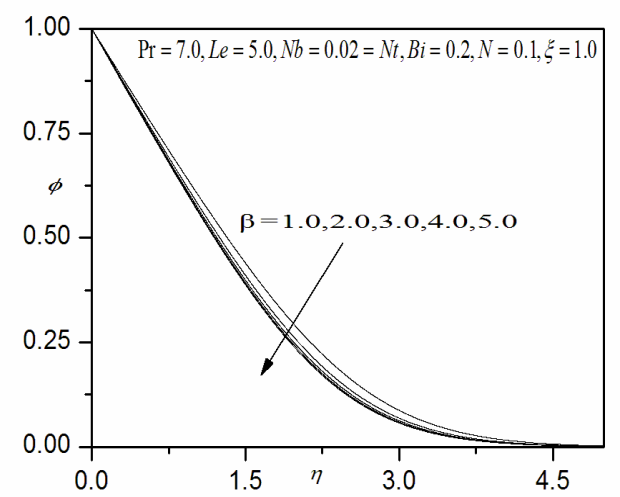

Fig 3(c): Effect of $\beta$ on concentration profiles

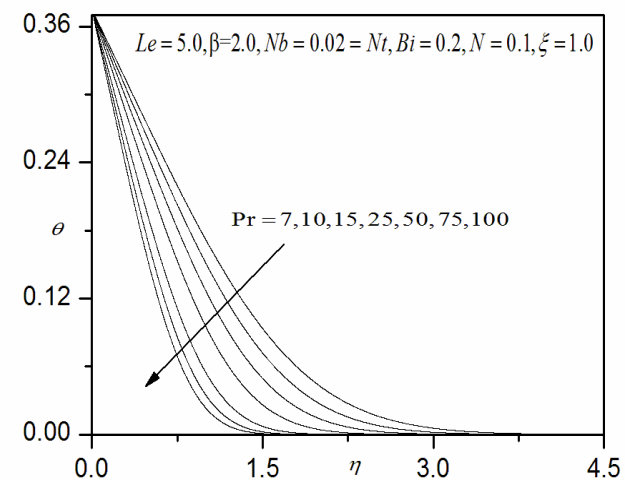

Fig 4(b): Effect of Pr on temperature profiles

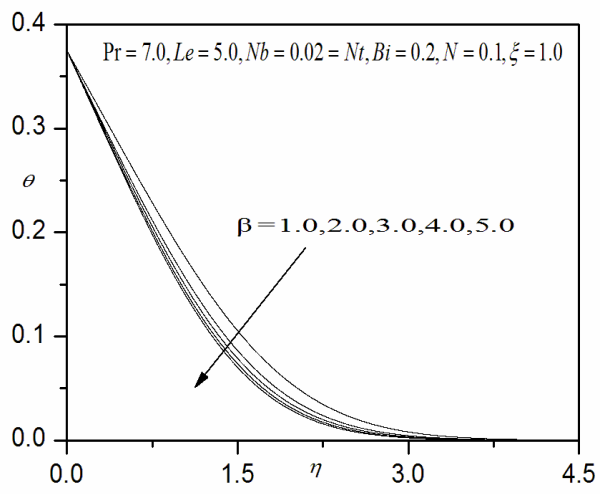

Fig 3(b): Effect of $\beta$ on temperature profiles

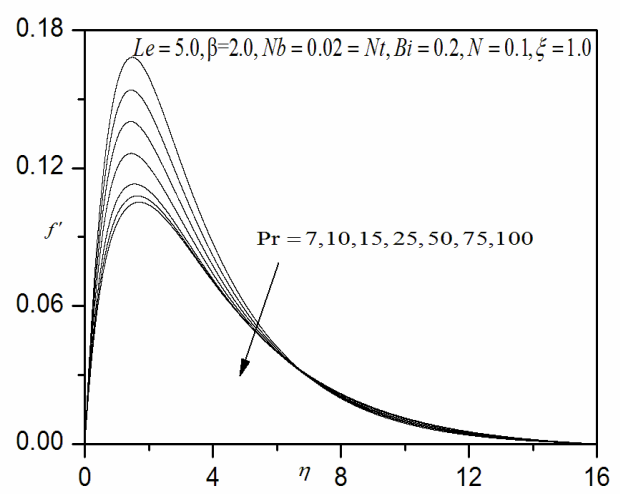

Fig 4(a): Effect of Pr on velocity profiles

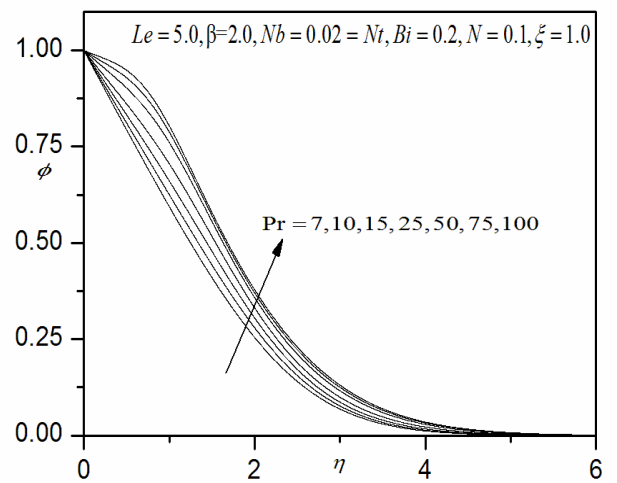

Fig 4(c): Effect of Pr on concentration profiles 


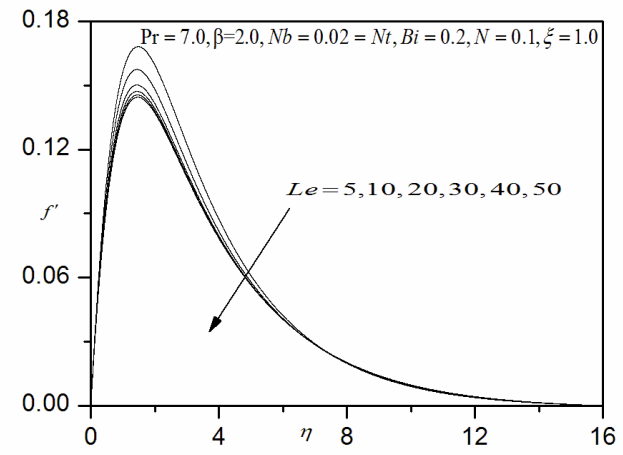

Fig 5(a): Effect of Le on velocity profiles

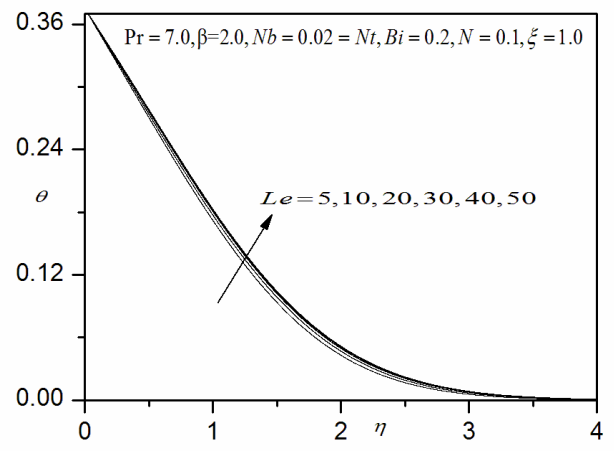

Fig 5(b): Effect of Le on temperature profiles

Figs. 5(a) $-5(\mathrm{c})$ illustrate the evolution of velocity, temperature and concentration functions with a variation in the Lewis number, is depicted. Lewis number is the ratio of thermal diffusivity to mass (Nano-particle) species diffusivity. $L e=1$ which physically implies that thermal diffusivity of the nanofluid and species diffusivity of the Nano-particles are the same and both boundary layer thicknesses are equivalent. For Le < 1, mass diffusivity exceeds thermal diffusivity and vice versa for Le $>1$. Both cases are examined in figs 5a-5c. In fig 5a, a consistently weak decrease in velocity accompanies an increase in Lewis number. Momentum boundary layer thickness is therefore increased with greater Lewis number. This is sustained throughout the boundary layer. Fig. 5b shows that increasing Lewis number also depresses the temperature magnitudes and therefore reduces thermal boundary layer thickness. Therefore judicious selection of Nano-particles during doping of polymers has a pronounced influence on velocity (momentum) and thermal characteristics in enrobing flow, since mass diffusivity is dependent on the nature of Nano-particle species in the base fluid. Fig $5 \mathrm{c}$ demonstrates that a more dramatic depression in Nano-particle concentration results from an increase in Lewis number over the same range as figs. 5a,b. The concentration profile evolves from approximately linear decay to strongly parabolic decay with increment in Lewis number.

Figs. 6(a) - 6(c) illustrate the variation of velocity, temperature and Nano-particle concentration with transverse coordinate $(\eta)$, for different values of Biot number $(B i)$. Biot number is imposed in the augmented wall boundary condition in eqn. (11). With increasing Biot Number, more heat is transmitted to the fluid and this energizes the boundary layer. This also leads to a general acceleration as obs erved in fig. $6 \mathrm{a}$ and also to a more pronounced restoration in temperatures in fig. $6 \mathrm{~b}$, in particular near the wall. The effect of Biot number is progressively reduced with further distance from the wall (curved surface) into the boundary layer and vanishes some distance before the free stream. It is also apparent from fig. 6c that nanoparticle concentration is enhanced with greater Biot number effect. Momentum boundary layer thickness is therefore reduced whereas thermal and species boundary layer thickness are enlarged. Evidently the non-trivial responses computed in figs. 6a-c further emphasize the need to incorporate Biot number effects in realistic nanofluid enrobing flows. A similar results observed in case of flow over vertical surface (2018).

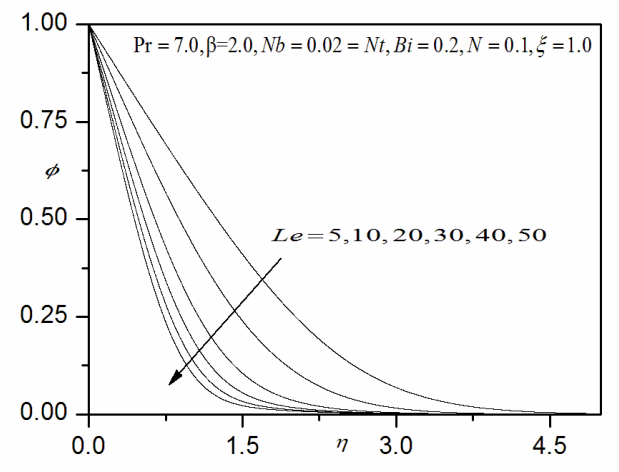

Fig 5(c): Effect of Le on concentration profiles

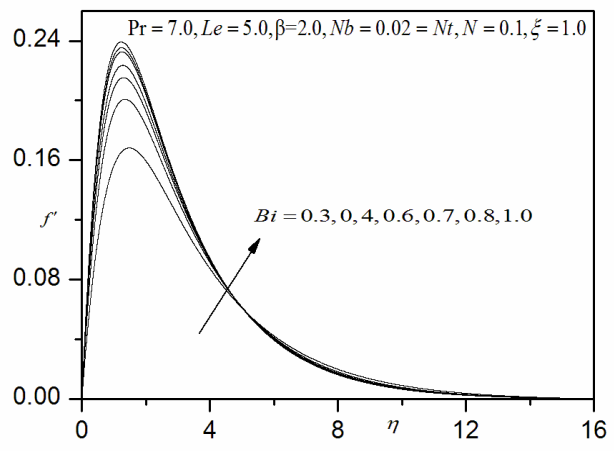

Fig 6(a): Effect of Bi on velocity profiles 


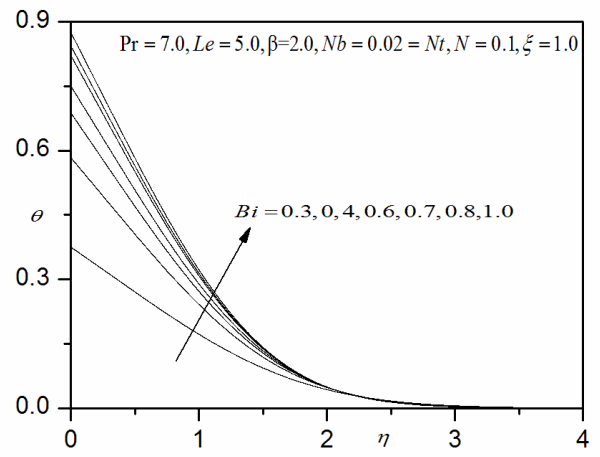

Fig 6(b): Effect of Bi on temperature profiles

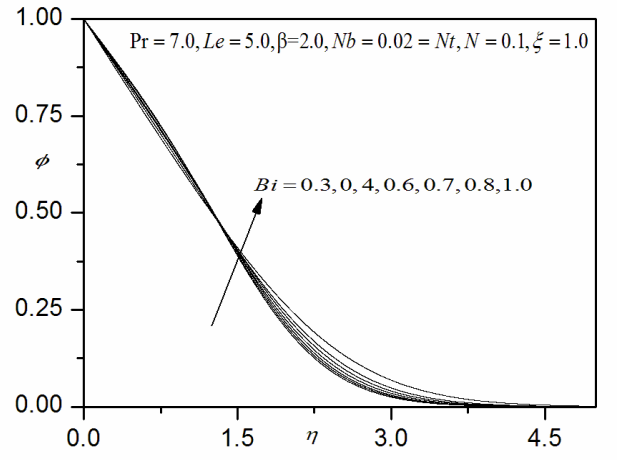

Fig 6(c): Effect of Bi on concentration profiles

Figs. 7(a) - 7(c) present the effects of the buoyancy ratio $\mathrm{N}$ on the velocity, temperature and nano-particle concentration profiles. In general, increases in the value of $\mathrm{N}$ have the prevalent to cause more induced flow along the cone surface. This behavior in the flow velocity increases in the fluid temperature and volume fraction species as well as slight decreased in the thermal and species boundary layers thickness as $\mathrm{N}$ increases.

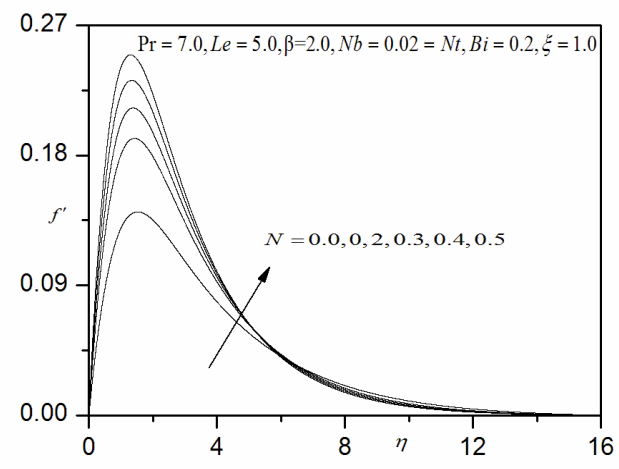

Fig 7(a): Effect of $\mathrm{N}$ on velocity profiles

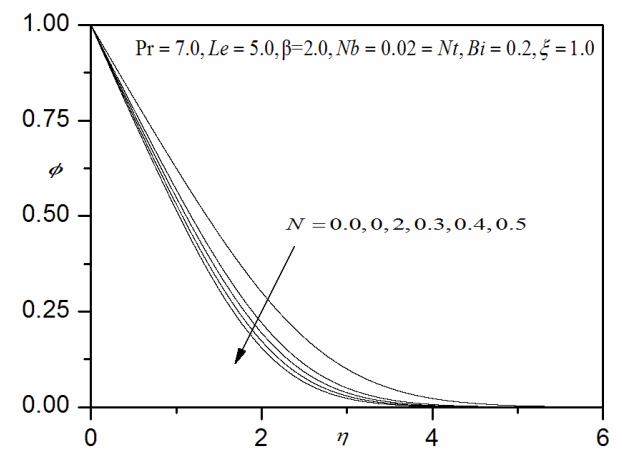

Fig 7(c): Effect of $\mathrm{N}$ on concentration profiles

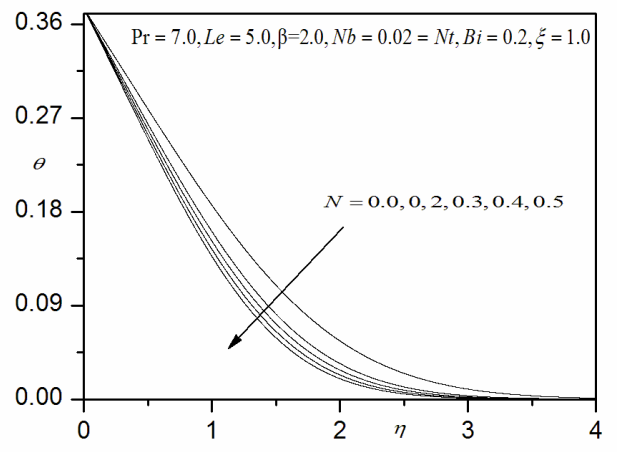

Fig 7(b): Effect of $\mathrm{N}$ on temperature profiles

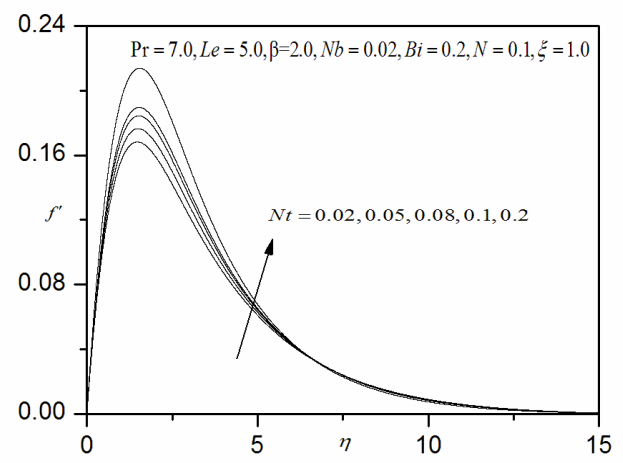

Fig 8(a): Effect of Nt on velocity profiles

Figs. 8(a) - 8(c) illustrates the effect of the thermophoresis parameter $(N t)$ on the velocity $\left(f^{\prime}\right)$, temperature $(\theta)$ and concentration $(\phi)$ distributions, respectively. Thermophoretic migration of Nano-particles results in exacerbated transfer of heat from the nanofluid regime to the cylinder surface. This de-energizes the boundary layer and inhibits simultaneously the diffusion of momentum, manifesting in a reduction in velocity i.e. retardation in the boundary layer flow and increasing momentum (hydrodynamic) boundary layer thickness, as 
computed in fig. 8a. Temperature is similarly decreased with greater thermophoresis parameter (fig. 8b). Conversely there is a substantial enhancement in Nano-particle concentration (and species boundary layer thickness) with greater $N t$ values. Similar observations have been made by Kunetsov and Nield (2014) and Ferdows et al. (2014) for respectively, both non-conducting Newtonian and electrically-conducting Newtonian flows.

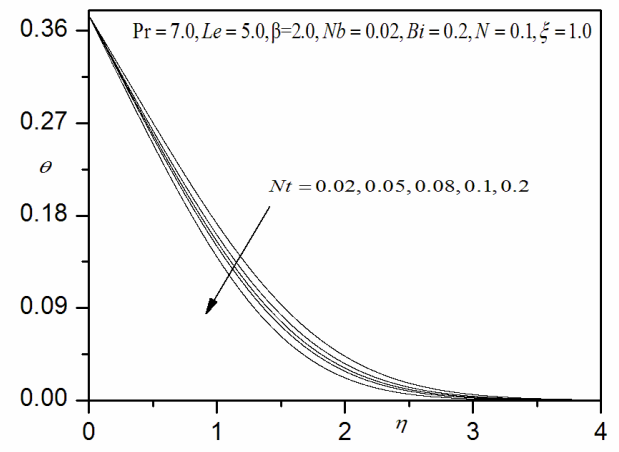

Fig 8(b): Effect of Nt on temperature profiles

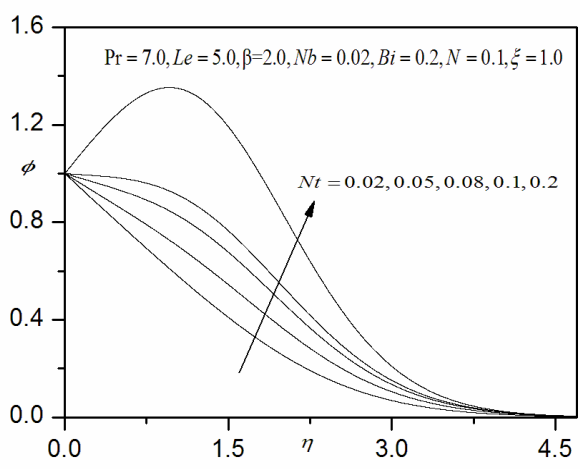

Fig 8(c): Effect of Nt on concentration profiles

Figs. 9(a) - 9(c) depict the response in velocity $\left(f^{\prime}\right)$, temperature $(\theta)$ and concentration $(\phi)$ functions to a variation in the Brownian motion parameter $(\mathrm{Nb})$. Increasing Brownian motion parameter physically correlates with smaller nanoparticle diameters, as elaborated in Rana et al. [11]. Smaller values of $N b$ corresponding to larger nanoparticles, and imply that surface area is reduced which in turn decreases thermal conduction heat transfer to the cylinder surface. This coupled with enhanced macro-convection within the nanofluid energizes the boundary layer and accelerates the flow as observed in fig. 9a. Similarly the energization of the boundary layer elevates thermal energy which increases temperature in the Viscoplastic nanofluid. Fig 9c however indicates that the contrary response is computed in the Nano-particle concentration field. With greater Brownian motion number species diffusion is suppressed. Effectively therefore momentum and nanoparticle concentration boundary layer thickness is decreased whereas thermal boundary layer thickness is increased with higher Brownian motion parameter values.

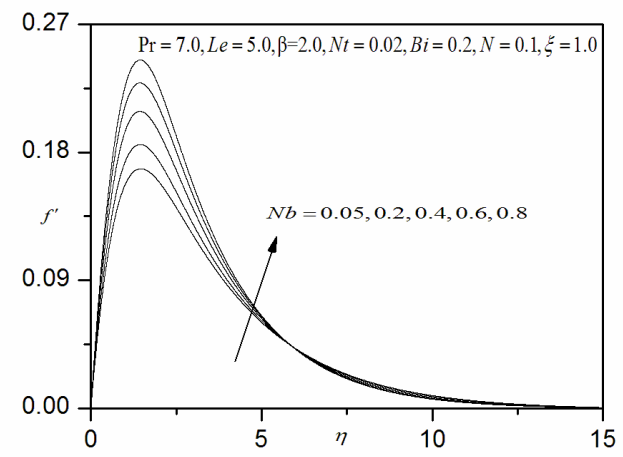

Fig 9(a): Effect of $\mathrm{Nb}$ on velocity profiles

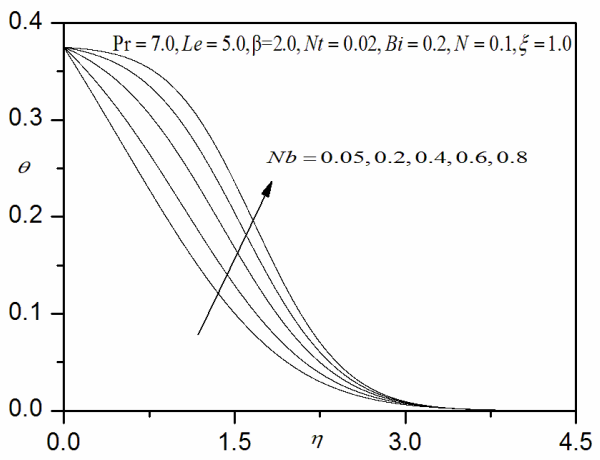

Fig 9(b): Effect of $\mathrm{Nb}$ on temperature profiles

Figs. 10(a) - 10(c) present the distributions for velocity, temperature and concentration fields with stream wise coordinate $\xi$, for the Viscoplastic nanofluid flow. Increasing $\xi$ values correspond to progression around the periphery of the cone, from the leading edge $(\xi=0)$. As $\xi$ increases, there is a weak deceleration in the flow (fig. 10a), which is strongest nearer the cone surface and decays with distance into the free stream. Conversely there is a weak elevation in temperatures (fig. 10b) and Nano-particle concentration magnitudes (fig. 10c) with increasing stream wise coordinate. 


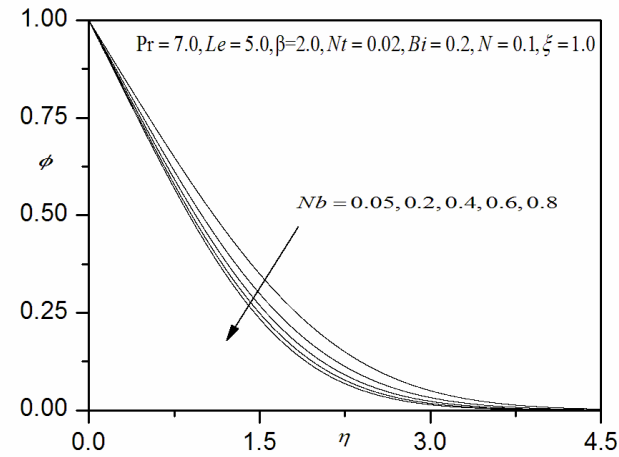

Fig 9(c): Effect of $\mathrm{Nb}$ on concentration profiles

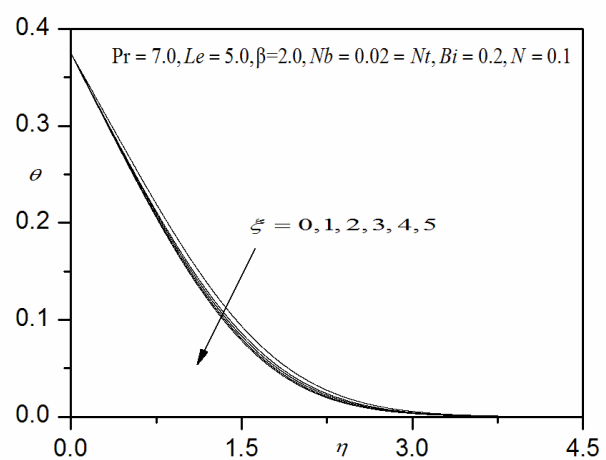

Fig 10(b): Effect of $\xi$ on temperature profiles

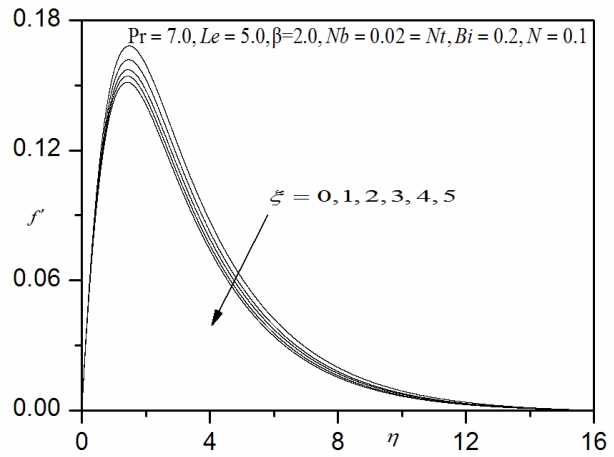

Fig 10(a): Effect of $\xi$ on velocity profiles

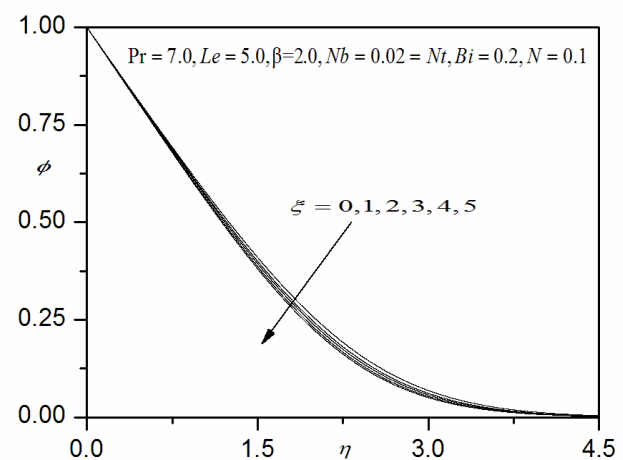

Fig 10(c): Effect of $\xi$ on concentration profiles

\section{Conclusions}

A theoretical study has been conducted to simulate the non-Newtonian Viscoplastic nanofluid boundary layer flow in enrobing processes over a truncated cone with Biot Number effect using the Buonjiornio formulation. The transformed momentum, heat and species boundary layer equations have been solved computationally with Keller's finite difference method. Computations have been verified with Nakamura's tridiagonal method. The present study has shown that:

(i) Increasing Viscoplastic (Casson) parameter accelerates the flow and also decreases thermal and Nanoparticle concentration boundary layer thickness.

(ii) Increasing Prandtl number retards the flow and also decreases temperatures and Nano-particle concentration values.

(iii) Increasing stream wise coordinate decelerates the flow whereas it enhances temperatures and species (Nano-particle) concentrations.

(iv) Increasing Biot Number effect strongly enriched velocities, temperatures and Nano-particle concentrations.

(v) Increasing Brownian motion accelerates the flow and enhances temperatures whereas it reduces nanoparticle concentration boundary layer thickness.

(vi) Increasing thermophoretic parameter increasing momentum boundary layer thickness and nanoparticle boundary layer thickness whereas it reduces thermal boundary layer thickness.

(vii) Increasing Buoyancy ratio parameter enhances the flow whereas it reduces temperature and Nano-particle (species) concentrations.

The current study has explored an interesting Viscoplastic model for nanomaterials which are currently of interest in aerospace coating applications. Time-dependent effects have been neglected. Future studies will therefore address transient enrobing Viscoplastic nanofluid transport phenomena for alternative geometries (wedges, spheres, plates), also of interest in aerospace materials fabrication and will be communicated imminently. 


\section{Acknowledgement}

The authors appreciate the constructive comments of the reviewers which led to definite improvement in the paper.

\section{References}

Ahmed, S.E. and Mahdy, A. (2012): Natural convection of flow and heat transfer enhancement of a nanofluid past a truncated cone with magnetic field effect, World J. Mech., Vol. 2, No. 5 pp. 272-279.

Amanulla, C.H., Nagendra, N., Subba Rao A., Anwar Bég O. and Kadir A. (2018): Numerical Exploration of Thermal Radiation and Biot Number Effects on the Flow of a Non-Newtonian MHD Williamson Fluid over a Vertical Convective Surface, Heat Trans Asian Res., Vol. 47, No. 2, pp. 286-304.

https://doi.org/10.1002/htj.21303

Amanulla, C.H., Nagendra, N. and Surya Narayana Reddy, M. (2017): Numerical Study of Thermal and Momentum Slip Effects on MHD Williams on Nanofluid from an Isothermal Sphere, Journal of Nanofluids, Vol. 6, No. 6, pp. 1111-1126.

https://doi.org/10.1166/jon.2017.1405

Amanulla, C.H., Nagendra, N. and Surya Narayana Reddy, M. (2018): Numerical Simulations on Magnetohydrodynamic Non-Newtonian Nanofluid Flow over a Semi-Infinite Vertical Surface with Slip effects, Journal of Nanofluids, Vol. 7, No. 4, pp. 718-730.

https://doi.org/10.1166/jon.2018.1499

Amanulla, C.H., Nagendra, N. and Suryanarayana Reddy, M. (2018): Computational Analysis of Non -Newtonian Boundary Layer Flow of Nanofluid Past a Semi-infinite Vertical Plate with Partial Slip, Nonlinear Engineering, Vol. 7, No.1, pp. 29-43.

https://doi.org/10.1515/nleng-2017-0055

Amanulla, C.H., Nagendra, N. and Suryanarayana Reddy, M. (2018): Numerical Simulation of Slip Influence on the Flow of a MHD Williams on Fluid Over a Vertical Convective Surface, Nonlinear Engineering, pp. 1-13. https://doi.org/10.1515/nleng-2017-0079

Amanulla, C.H., Nagendra, N. and Suryanarayana Reddy, M. (2017): MHD Flow and Heat Transfer in a Williamson Fluid from a Vertical Permeable Cone with Thermal and Momentum Slip Effects: A Mathematical Study, Frontiers in Heat and Mass Transfer, Vol. 8, 40, Pp. 1-11. http://dx.doi.org/10.5098/h mt.8.40

Amanulla, C.H., Nagendra, N. and Suryanarayana Reddy, M. (2017): Thermal and Momentum Slip Effects on Hydromagnetic Convection Flow of a Williamson Fluid Past a Vertical Truncated Cone, Frontiers in Heat and Mass Transfer, Vol. 9, 22, pp.

https://doi.org/10.5809/hmt.9.22

Bég, O.A., Gaffar, S.A., Prasad, V.R and Uddin, M.J. (2016): Computational solutions for non-isothermal, nonlinear magneto-convection in porous media with Hall/ionslip currents and Ohmic dissipation, Engineering Science and Technology, an International Journal, Vol. 19, Issue. 1, pp. 377-394.

http://dx.doi.org/10.1016/j.jestch.2015.08.009

Bég, O.A. (2013): NANONAK- A finite difference code for nanofluid convection problems of the boundary layer type, Technical Report, NANO-C/5-1, 124 pages, Gort Engovation, Bradford, England and Narvik, Norway, UK.

Bég, O.A., Zueco, J., Norouzi, M., Davoodi, M., Joneidi, A.A. and Elsayed A.F. (2014): Network and Nakamura tridiagonal computational simulation of electrically-conducting biopolymer micro-morphic transport phenomena, Computers in Biology and Medicine, Vol. 44, pp. 44-56.

http://dx.doi.org/10.1016/j.compbiomed.2013.10.026

Buongiorno, J (2006). Convective transport in nanofluids, ASME Journal of Heat Trans, Vol.128, No. 3, pp. 240-250. http://dx.doi.org/10.1115/1.2150834.

Casson, N. (1959): Rheology of Disperse Systems, Ed. C.C. Mill, Pergamon Press, Oxford.

Choi, S. (1995): Enhancing thermal conductivity of fluids with nanoparticles ASME-Publ. Fluids Engineering Division, Vol. 231, pp. 99-106.

Choi, S.U.S. and Eastman, J.A. (1995): Enhancing thermal conductivity of fluids with nanoparticles, ASME International Mechanical Engineering Congress \& Exposition, San Francisco, USA, Vol. 66, pp. 99-105.

Ferdows, M., Khan, M.S., Bég, O.A., Azad, M. and Alam, M.M. (2014): Numerical study of transient magnetohydrodynamic radiative free convection nanofluid flow from a stretching permeable surface, Proc. IMechE-Part E: J. Process Mechanical Engineering, Vol.228, pp. 181-196. http://dx.doi.org/10.1177/0954408913493406 
Kolsi, L., Hussein, A.K.., Borjini, M., Mohammed, H. and Ben Aïssia, H. (2014) Computational analysis of three-dimensional unsteady natural convection and entropy generation in a cubical enclosure filled with water$\mathrm{Al}_{2} \mathrm{O}_{3}$ nanofluid, Arabian Journal for Science and Engineering, Vol. 39, pp. 7483-7493.

Hussain, T., Shehzad, S.A., Alsaedi, A., Hayat, T. and Ramzan, M. (2015): Flow of Casson nanofluid with viscous dissipation and convective conditions: A mathematical model, Journal of Central South University, Vol. 22, Is sue. 3, pp. 1132-1140.

http://dx.doi.org/10.1007/s 11771-015-2625-4

Keller, H.B. (1970): A new difference method for parabolic problems, J. Bramble (Editor), Numerical Methods for Partial Differential Equations, Academic Press, New York, USA.

Kleinstreuer, C. and Feng, Y. (2011): Experimental and theoretical studies of nanofluid thermal conductivity enhancement: a review, Nanoscale Research Letters, Vol. 6, 229.

http://dx.doi.org/10.1186/1556-276X-6-229

Kunetsov, A.V. and Nield, D.A. (2014): Natural convective boundary layer flow of a nanofluid past a vertical plate: a revised model, International Journal of Thermal Sciences, Vol. 77, pp. 126-129.

http://dx.doi.org/10.1016/j.ijthermalsci.2013.10.007

Kuznetsov, A.V. and Nield, D.A. (2010): Natural convective boundary-layer flow of a nanofluid past a vertical plate, International Journal of Thermal Sciences, Vol. 49, Is sue. 2, pp. 243-247.

http://dx.doi.org/10.1016/j.ijthermalsci.2013.10.007

Chand, R., Rana, G. and Hussein, A.K. (2015): Effect of Suspended Particles on the Onset of Thermal Convection in a Nanofluid Layer for More Realistic Boundary Conditions, International Journal of Fluid Mechanics Research, Vol. 42, No. 5, pp. 375-390.

Mahatha, B. K., Nandkeolyar, R., Mahto, G. K. and Sibanda, P. (2016): A Dissipative Effects in Hydromagnetic Boundary Layer Nanofluid Flow past a Stretching Sheet with Newtonian Heating, Journal of Applied Fluid Mechanics, Vol. 9, Issue. 4, pp. 1977-1989.

Malik, M.Y., Naseer, M., Nadeem, S. and Abdul, R. (2014): The boundary layer flow of Casson nanofluid over a vertical exponentially stretching cylinder, Applications in Nanoscience., Vol. 4, No. 7, pp. 869-873.

http://dx.doi:10.1007/s 13204-013-0267-0.

Mustafa, M. and Khan, J.A. (2015): Model for flow of Casson nanofluid past a $\mathrm{n}$ on-linearly stretching sheet considering magnetic field effects, AIP Advances, Vol. 5, 077148. http://dx.doi.org/10.1063/1.4927449

Nakamura, S. (1994): Iterative finite difference schemes for similar and non-similar boundary layer equations, Advances in Engineering Software, Vol. 21, pp. 123-130.

Prasad, V.R., Gaffar, S.A. and Bég, O.A. (2015): Non-similar computational solutions for free convection boundary-layer flow of a nanofluid from an isothermal sphere in a non-Darcy porous medium, Journal of Nanofluids, Vol. 4, pp. 203-213. http://dx.doi.org/10.1166/jon.2015.1149

Ram Reddy, C H. and Pradeepa, T. (2016): Non- similarity solution of micropolar fluid flow over a truncated cone with Soret and viscous dissipation effects using spectral quasilinearization method, International Journal of Applied and Computational Mathematics, Vol. 3, No. 3, pp. 1763-1777. https://doi.org/10.1007/s40819-016$\underline{0227-y}$

Rana, P., Bhargava, R., Bég, O.A. and Kadir, A. (2016): Finite element analysis of viscoelastic nanofluid flow with energy dissipation and internal heat source/sink effects, International Journal of Applied and Computational Mathematics, pp. 1-27. http://dx.doi.org/10.1007/s40819-016-0184-5

Ahmed, S., Hussein, A.K., Mohammed, H, and Sivasankaran, S. (2014): Boundary layer flow and heat transfer due to permeable stretching tube in the presence of heat source/sink utilizing nanofluids, Applied Mathematics and Computation, Vol. 238, pp. 149-162.

Uddin, M.J., Khan, W.A., Ismail, A.I.M. and Bég, O.A. (2016): Computational study of three-dimensional stagnation point nanofluid bioconvection flow on a moving surface with anisotropic slip and thermal jump effect, ASME Journal of Heat Transfer., Vol.138, Is sue. 10. http://dx.doi:10.1115/1.4033581.

Hussein, A.K., Ashorynejad, H., Shikholeslami, M, and Sivasankaran, S. (2014): Lattice Boltzmann simulation of natural convection heat transfer in an open enclosure filled with $\mathrm{Cu}$-water nanofluid in a presence of magnetic field, Nuclear Engineering and Design, Vol. 268, pp. 10-17.

Yih, K.A. (1999): Effect of radiation on natural convection about a truncated cone. International Journal of Heat Mass Transfer., Vol. 42, pp.4299-4305. 